\title{
Effect of Stagnation Temperature on Supersonic Flow Parameters with Application for Air in Nozzles
}

\author{
Toufik Zebbiche \\ University SAAD Dahleb of Blida, \\ Algeria
}

\section{Introduction}

The obtained results of a supersonic perfect gas flow presented in (Anderson, 1982, 1988 \& Ryhming, 1984), are valid under some assumptions. One of the assumptions is that the gas is regarded as a calorically perfect, i. e., the specific heats $C_{P}$ is constant and does not depend on the temperature, which is not valid in the real case when the temperature increases (Zebbiche \& Youbi, 2005b, 2006, Zebbiche, 2010a, 2010b). The aim of this research is to develop a mathematical model of the gas flow by adding the variation effect of $C_{P}$ and $\gamma$ with the temperature. In this case, the gas is named by calorically imperfect gas or gas at high temperature. There are tables for air (Peterson \& Hill, 1965) for example) that contain the values of $C_{P}$ and $\gamma$ versus the temperature in interval $55 \mathrm{~K}$ to $3550 \mathrm{~K}$. We carried out a polynomial interpolation of these values in order to find an analytical form for the function $C_{P}(T)$.

The presented mathematical relations are valid in the general case independently of the interpolation form and the substance, but the results are illustrated by a polynomial interpolation of the 9th degree. The obtained mathematical relations are in the form of nonlinear algebraic equations, and so analytical integration was impossible. Thus, our interest is directed towards to the determination of numerical solutions. The dichotomy method for the solution of the nonlinear algebraic equations is used; the Simpson's algorithm (Démidovitch \& Maron, 1987 \& Zebbiche \& Youbi, 2006, Zebbiche, 2010a, $2010 \mathrm{~b}$ ) for numerical integration of the found functions is applied. The integrated functions have high gradients of the interval extremity, where the Simpson's algorithm requires a very high discretization to have a suitable precision. The solution of this problem is made by introduction of a condensation procedure in order to refine the points at the place where there is high gradient. The Robert's condensation formula presented in (Fletcher, 1988) was chosen. The application for the air in the supersonic field is limited by the threshold of the molecules dissociation. The comparison is made with the calorically perfect gas model.

The problem encounters in the aeronautical experiments where the use of the nozzle designed on the basis of the perfect gas assumption, degrades the performances. If during the experiment measurements are carried out it will be found that measured parameters are differed from the calculated, especially for the high stagnation temperature. Several reasons 
are responsible for this deviation. Our flow is regarded as perfect, permanent and nonrotational. The gas is regarded as calorically imperfect and thermally perfect. The theory of perfect gas does not take account of this temperature.

To determine the application limits of the perfect gas model, the error given by this model is compared with our results.

\section{Mathematical formulation}

The development is based on the use of the conservation equations in differential form. We assume that the state equation of perfect gas $(P=\rho R T)$ remains valid, with $R=287.102 \mathrm{~J} /(\mathrm{kg}$ $\mathrm{K})$. For the adiabatic flow, the temperature and the density of a perfect gas are related by the following differential equation (Moran, 2007 \& Oosthuisen \& Carscallen, 1997 \& Zuker \& Bilbarz, 2002, Zebbiche, 2010a, 2010b).

$$
\frac{C_{P}}{\gamma} d T-\frac{R T}{\rho} d \rho=0
$$

Using relationship between $C_{P}$ and $\gamma\left[C_{P}=\gamma R /(\gamma-1)\right]$, the equation (1) can be written at the following form:

$$
\frac{d \rho}{\rho}=\frac{d T}{T[\gamma(T)-1]}
$$

The integration of the relation (2) gives the adiabatic equation of a perfect gas at high temperature.

The sound velocity is (Ryhming, 1984),

$$
a^{2}=\left(\frac{d P}{d \rho}\right)_{\text {entropy }=\text { cons } \tan t}
$$

The differentiation of the state equation of a perfect gas gives:

$$
\frac{d P}{d \rho}=\rho R \frac{d T}{d \rho}+R T
$$

Substituting the relationship (2) in the equation (4), we obtain after transformation:

$$
a^{2}(T)=\gamma(T) R T
$$

Equation (5) proves that the relation of speed of sound of perfect gas remains always valid for the model at high temperature, but it is necessary to take into account the variation of the ratio $\gamma(T)$.

The equation of the energy conservation in differential form (Anderson, 1988 \& Moran, 2007) is written as:

$$
C_{P} d T+V d V=0
$$

The integration between the stagnation state $\left(V_{0} \approx 0, T_{0}\right)$ and supersonic state $(V, T)$ gives: 


$$
V^{2}=2 H(T)
$$

Where

$$
H(T)=\int_{T}^{T_{0}} C_{P}(T) d T
$$

Dividing the equation (6) by $V^{2}$ and substituting the relation (7) in the obtained result, we obtain:

$$
\frac{d V}{V}=-\frac{C_{P}(T)}{2 H(T)} d T
$$

Dividing the relation (7) by the sound velocity, we obtain an expression connecting the Mach number with the enthalpy and the temperature:

$$
M(T)=\frac{\sqrt{2 H(T)}}{a(T)}
$$

The relation (10) shows the variation of the Mach number with the temperature for calorically imperfect gas.

The momentum equation in differential form can be written as (Moran, 2007, Peterson \& Hill1, 1965, \& Oosthuisen \& Carscallen, 1997):

$$
V d V+\frac{d P}{\rho}=0
$$

Using the expression (3), the relationship (10), can be written as:

$$
\frac{d \rho}{\rho}=F_{\rho}(T) d T
$$

Where

$$
F_{\rho}(T)=\frac{C_{P}(T)}{a^{2}(T)}
$$

The density ratio relative to the temperature $T_{0}$ can be obtained by integration of the function (13) between the stagnation state $\left(\rho_{0}, T_{0}\right)$ and the concerned supersonic state $(\rho, T)$ :

$$
\frac{\rho}{\rho_{0}}=\operatorname{Exp}\left(-\int_{T}^{T_{0}} F_{\rho}(T) d T\right)
$$

The pressure ratio is obtained by using the relation of the perfect gas state: 


$$
\frac{P}{P_{0}}=\left(\frac{\rho}{\rho_{0}}\right)\left(\frac{T}{T_{0}}\right)
$$

The mass conservation equation is written as (Anderson, 1988 \& Moran, 2007)

$$
\rho V A=\text { constan } t
$$

The taking logarithm and then differentiating of relation (16), and also using of the relations (9) and (12), one can receive the following equation:

$$
\begin{gathered}
\frac{d A}{A}=F_{A}(T) d T \\
F_{A}(T)=C_{P}(T)\left[\frac{1}{a^{2}(T)}-\frac{1}{2 H(T)}\right]
\end{gathered}
$$

The integration of equation (17) between the critical state $\left(A_{*}, T_{*}\right)$ and the supersonic state $(A$, $T)$ gives the cross-section areas ratio:

$$
\frac{A}{A_{*}}=\operatorname{Exp}\left(\int_{T}^{T *} F_{A}(T) d T\right)
$$

To find parameters $\rho$ and $A$, the integrals of functions $F_{\rho}(T)$ and $F_{A}(T)$ should be found. As the analytical procedure is impossible, our interest is directed towards the numerical calculation. All parameters $M, \rho$ and A depend on the temperature.

The critical mass flow rate (Moran, 2007, Zebbiche \& Youbi, 2005a, 2005b) can be written in non-dimensional form:

$$
\frac{m}{A_{*} \rho_{0} a_{0}}=\int_{. A}\left(\frac{\rho}{\rho_{0}}\right)\left(\frac{a}{a_{0}}\right) M \cos (\theta) \frac{d A}{A_{*}}
$$

As the mass flow rate through the throat is constant, we can calculate it at the throat. In this section, we have $\rho=\rho_{*}, a=a_{*}, M=1, \theta=0$ and $A=A *$. Therefore, the relation (20) is reduced to:

$$
\frac{\dot{m}}{A_{*} \rho_{0} a_{0}}=\left(\frac{\rho_{*}}{\rho_{0}}\right)\left(\frac{a_{*}}{a_{0}}\right)
$$

The determination of the velocity sound ratio is done by the relation (5). Thus,

$$
\frac{a}{a_{0}}=\left[\frac{r(T)}{r\left(T_{0}\right)}\right]^{1 / 2}\left[\frac{T}{T_{0}}\right]^{1 / 2}
$$

The parameters $T, P, \rho$ and $A$ for the perfect gas are connected explicitly with the Mach number, which is the basic variable for that model. For our model, the basic variable is the temperature because of the implicit equation (10) connecting $M$ and $T$, where the reverse analytical expression does not exist. 


\section{Calculation procedure}

In the first case, one presents the table of variation of $C_{P}$ and $\gamma$ versus the temperature for air (Peterson \& Hill, 1965, Zebbiche 2010a, 2010b). The values are presented in the table 1.

\begin{tabular}{|c|c|c|c|c|c|c|c|c|}
\hline $\mathrm{T}(\mathrm{K})$ & $\begin{array}{c}\mathrm{C}_{\mathrm{P}} \\
(\mathrm{J} /(\mathrm{KgK})\end{array}$ & $\gamma(\mathrm{T})$ & $\mathrm{T}(\mathrm{K})$ & $\begin{array}{c}\mathrm{C}_{\mathrm{P}} \\
(\mathrm{J} /(\mathrm{Kg} \mathrm{K})\end{array}$ & $\gamma(\mathrm{T})$ & $\mathrm{T}(\mathrm{K})$ & $\begin{array}{c}\mathrm{C}_{\mathrm{P}} \\
\mathrm{J} /(\mathrm{Kg} \mathrm{K})\end{array}$ & $\gamma(\mathrm{T})$ \\
\hline 55.538 & 1001.104 & 1.402 & 833.316 & 1107.192 & 1.350 & 2111.094 & 1256.813 & 1.296 \\
\hline . & $\cdot$ & & 888.872 & 1119.078 & 1.345 & 2222.205 & 1263.410 & 1.294 \\
\hline 222.205 & 1001.101 & 1.402 & 944.427 & 1131.314 & 1.340 & 2333.316 & 1270.097 & 1.292 \\
\hline 277.761 & 1002.885 & 1.401 & 999.983 & 1141.365 & 1.336 & 2444.427 & 1273.476 & 1.291 \\
\hline 305.538 & 1004.675 & 1.400 & 1055.538 & 1151.658 & 1.332 & 2555.538 & 1276.877 & 1.290 \\
\hline 333.316 & 1006.473 & 1.399 & 1111.094 & 1162.202 & 1.328 & 2666.650 & 1283.751 & 1.288 \\
\hline 361.094 & 1008.281 & 1.398 & 1166.650 & 1170.280 & 1.325 & 2777.761 & 1287.224 & 1.287 \\
\hline 388.872 & 1011.923 & 1.396 & 1222.205 & 1178.509 & 1.322 & 2888.872 & 1290.721 & 1.286 \\
\hline 416.650 & 1015.603 & 1.394 & 1277.761 & 1186.893 & 1.319 & 2999.983 & 1294.242 & 1.285 \\
\hline 444.427 & 1019.320 & 1.392 & 1333.316 & 1192.570 & 1.317 & 3111.094 & 1297.789 & 1.284 \\
\hline 499.983 & 1028.781 & 1.387 & 1444.427 & 1204.142 & 1.313 & 3222.205 & 1301.360 & 1.283 \\
\hline 555.538 & 1054.563 & 1.374 & 1555.538 & 1216.014 & 1.309 & 3333.316 & 1304.957 & 1.282 \\
\hline 611.094 & 1054.563 & 1.370 & 1666.650 & 1225.121 & 1.306 & 3444.427 & 1304.957 & 1.282 \\
\hline 666.650 & 1067.077 & 1.368 & 1777.761 & 1234.409 & 1.303 & 3555.538 & 1308.580 & 1.281 \\
\hline 722.205 & 1080.005 & 1.362 & 1888.872 & 1243.883 & 1.300 & & & \\
\hline 777.761 & 1093.370 & 1.356 & 1999.983 & 1250.305 & 1.298 & & & \\
\hline
\end{tabular}

Table 1. Variation of $C_{P}(T)$ and $\gamma(T)$ versus the temperature for air.

For a perfect gas, the $\gamma$ and $C_{P}$ values are equal to $\gamma=1.402$ and $C_{P}=1001.28932 \mathrm{~J} /(\mathrm{kgK})$ (Oosthuisen \& Carscallen, 1997, Moran, 2007 \& Zuker \& Bilbarz, 2002).. The interpolation of the $C_{P}$ values according to the temperature is presented by relation (23) in the form of Horner scheme to minimize the mathematical operations number (Zebbiche, 2010a, 2010b):

$$
C_{P}(T)=a_{1}+T\left(a_{2}+T\left(a_{3}+T\left(a_{4}+T\left(a_{5}+T\left(a_{6}+T\left(a_{7}+T\left(a_{8}+T\left(a_{9}+T\left(a_{10}\right)\right)\right)\right)\right)\right)\right)\right)\right)
$$

The interpolation $\left(a_{i} i=1,2, \ldots, 10\right)$ of constants are illustrated in table 2 .

\begin{tabular}{|c|c|}
\hline$I$ & $a_{i}$ \\
\hline 1 & 1001.1058 \\
2 & 0.04066128 \\
3 & -0.000633769 \\
4 & $2.74747510^{-6}$ \\
5 & $-4.03384510^{-9}$ \\
\hline
\end{tabular}

\begin{tabular}{|c|c|}
\hline$I$ & $a_{i}$ \\
\hline 6 & $3.06977310^{-12}$ \\
7 & $-1.35093510^{-15}$ \\
8 & $3.47226210^{-19}$ \\
9 & $-4.84675310^{-23}$ \\
10 & $2.84118710^{-27}$ \\
\hline
\end{tabular}

Table 2. Coefficients of the polynomial $C_{P}(T)$. 
A relationship (23) gives undulated dependence for temperature approximately low than $\overline{\mathrm{T}}=240 \mathrm{~K}$. So for this field, the table value (Peterson \& Hill, 1965), was taken

$$
\bar{C}_{P}=C_{p}(\bar{T})=1001.15868 \mathrm{~J} /(\mathrm{kg} \mathrm{K})
$$

Thus:

for $\quad T \leq \bar{T}$, we have $C_{P}(T)=\bar{C}_{P}$

for $T>\bar{T}$, relation (23) is used.

The selected interpolation gives an error less than $\varepsilon^{=10^{-3}}$ between the table and interpolated values.

Once the interpolation is made, we determine the function $H(T)$ of the relation (8), by integrating the function $C_{P}(T)$ in the interval $\left[T, T_{0}\right]$. Then, $H(T)$ is a function with a parameter $T_{0}$ and it is defined when $T \leq T_{0}$.

Substituting the relation (23) in (8) and writing the integration results in the form of Horner scheme, the following expression for enthalpy is obtained

$$
\begin{aligned}
& H(T)=H_{0}- \\
& \left.\left[c_{1}+T\left(c_{2}+T\left(c_{3}+T\left(c_{4}+T\left(c_{5}+T c_{6}+T\left(c_{7}+T\left(c_{8}+T\left(c_{9}+T\left(c_{10}\right)\right)\right)\right)\right)\right)\right)\right)\right)\right]
\end{aligned}
$$

Where

$$
\begin{aligned}
& H_{0}=T_{0}\left(c_{1}+T_{0}\left(c_{2}+T_{0}\left(c_{3}+T_{0}\left(c_{4}+T_{0}\left(c_{5}+T_{0}\left(c_{6}+\right.\right.\right.\right.\right.\right. \\
& \left.\left.\left.\left.\left.\left.T_{0}\left(c_{7}+T_{0}\left(c_{8}+T_{0}\left(c_{9}+T_{0}\left(c_{10}\right)\right)\right)\right)\right)\right)\right)\right)\right)\right)
\end{aligned}
$$

and

$$
c_{i}=\frac{a_{i}}{i} \quad(i=1,2,3, \ldots, 10)
$$

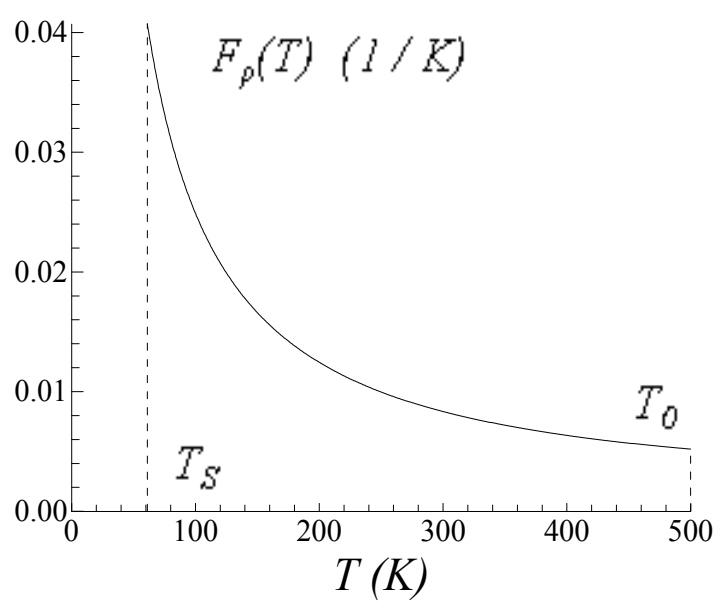

Fig. 1. Variation of function $F_{\rho}(T)$ in the interval $\left[T_{S}, T_{0}\right]$ versus $T_{0}$. 
Taking into account the correction made to the function $C_{P}(T)$, the function $H(T)$ has the following form:

For

$T_{0}<\bar{T}, H(T)=\bar{C}_{P}\left(T_{0}-T\right)$

For

$T_{0}>\bar{T}$, we have two cases:

$$
\begin{array}{lll}
\text { if } \quad T>\bar{T} & : H(T)=\text { relation }(24) \\
\text { if } \quad T \leq \bar{T} & : \quad H(T)=\bar{C}_{P}(\bar{T}-T)+H(\bar{T})
\end{array}
$$

The determination of the ratios (14) and (19) require the numerical integration of $F_{\rho}(T)$ and $F_{A}(T)$ in the intervals $\left[T, T_{0}\right]$ and $\left[T, T_{*}\right]$ respectively. We carried out preliminary calculation of these functions (Figs. 1, 2) to see their variations and to choice the integration method.

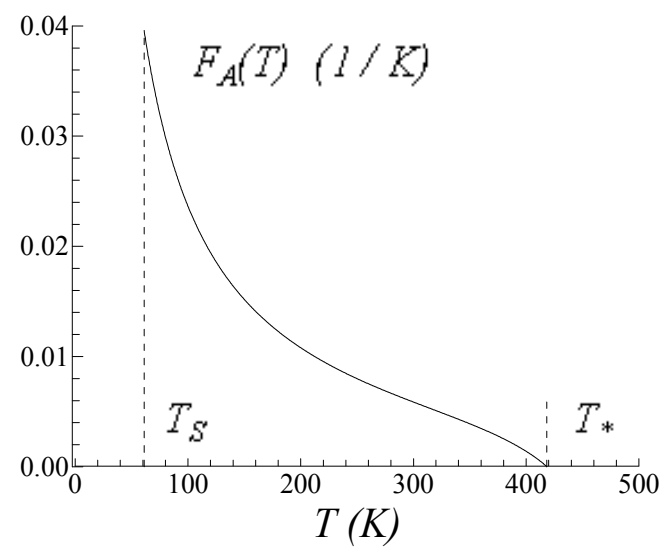

Fig. 2. Variation of the function $F_{A}(T)$ in the interval $\left[T_{S}, T_{*}\right]$ versus $T_{0}$

Due to high gradient at the left extremity of the interval, the integration with a constant step requires a very small step. The tracing of the functions is selected for $T_{0}=500 \mathrm{~K}$ (low temperature) and $M_{S}=6.00$ (extreme supersonic) for a good representation in these ends. In this case, we obtain $T_{*}=418.34 \mathrm{~K}$ and $T_{S}=61.07 \mathrm{~K}$. the two functions presents a very large derivative at temperature $T_{S}$.

A Condensation of nodes is then necessary in the vicinity of $T_{S}$ for the two functions. The goal of this condensation is to calculate the value of integral with a high precision in a reduced time by minimizing the nodes number. The Simpson's integration method (Démidovitch \& Maron, 1987 \& Zebbiche \& Youbi, 2006) was chosen. The chosen condensation function has the following form (Zebbiche \& Youbi, 2005a):

$$
s_{i}=b_{1} z_{i}+\left(1-b_{1}\right)\left[1-\frac{\tanh \left[b_{2} \cdot\left(1-z_{i}\right)\right]}{\tanh \left(b_{2}\right)}\right]
$$

Where

$$
z_{i}=\frac{i-1}{N-1} \quad 1 \leq i \leq N
$$

Obtained $s_{i}$ values, enable to find the value of $T_{i}$ in nodes $i$ : 


$$
T_{i}=s_{i}\left(T_{D}-T_{G}\right)+T_{G}
$$

The temperature $T_{D}$ is equal to $T_{0}$ for $F_{\rho}(T)$, and equal to $T *$ for $F_{A}(T)$. The temperature $T_{G}$ is equal to $T *$ for the critical parameter, and equal to $T_{S}$ for the supersonic parameter. Taking a value $b_{1}$ near zero $\left(b_{1}=0.1\right.$, for example $)$ and $b_{2}=2.0$, it can condense the nodes towards left edge $T_{S}$ of the interval, see figure 3 .

$$
\begin{array}{ll}
b_{1}=0.1 & , b_{2}=2.0 \\
b_{1}=1.0 & , b_{2}=2.0 \\
b_{1}=1.9 & , b_{2}=2.0
\end{array}
$$

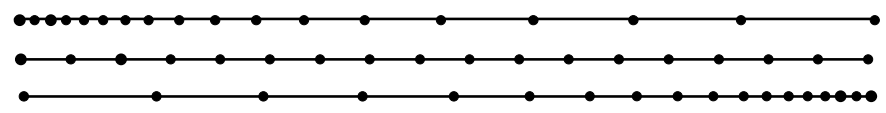

Fig. 3. Presentation of the condensation of nodes

\subsection{Critical parameters}

The stagnation state is given by $M=0$. Then, the critical parameters correspond to $M=1.00$, for example at the throat of a supersonic nozzle, summarize by:

When $M=1.00$ we have $T=T *$ These conditions in the relation (10), we obtain:

$$
2 H\left(T_{*}\right)-a^{2}\left(T_{*}\right)=0
$$

The resolution of equation (29) is made by the use of the dichotomy algorithm (Démidovitch \& Maron, 1987 \& Zebbiche \& Youbi, 2006), with $T * T_{0}$. It can choose the interval $\left[T_{1}, T_{2}\right]$ containing $T *$ by $T_{1}=0 \mathrm{~K}$ and $T_{2}=T_{0}$. The value $T *$ can be given with a precision $\varepsilon$ if the interval of subdivision number $K$ is satisfied by the following condition:

$$
K=1.4426 \log \left(\frac{T_{0}}{\varepsilon}\right)+1
$$

If $\varepsilon=10^{-8}$ is taken, the number $K$ cannot exceed 39. Consequently, the temperature ratio $T_{*} / T_{0}$ can be calculated.

Taking $T=T *$ and $\rho=\rho *$ in the relation (14) and integrating the function $F_{\rho}(T)$ by using the Simpson's formula with condensation of nodes towards the left end, the critical density ratio is obtained.

The critical ratios of the pressures and the sound velocity can be calculated by using the relations (15) and (22) respectively, by replacing $T=T_{*}, \rho=\rho_{*}, P=P_{*}$ and $a=a_{*}$,

\subsection{Parameters for a supersonic Mach number}

For a given supersonic cross-section, the parameters $\rho=\rho_{S}, P=P_{S}, A=A_{S}$, and $T=T_{S}$ can be determined according to the Mach number $M=M_{S}$. Replacing $T=T_{S}$ and $M=M_{S}$ in relation (10) gives

$$
2 H\left(T_{S}\right)-M_{S}^{2} a^{2}\left(T_{S}\right)=0
$$

The determination of $T_{S}$ of equation (31) is done always by the dichotomy algorithm, excepting $T_{S}<T_{*}$. We can take the interval $\left[T_{1}, T_{2}\right]$ containing $T_{S}$, by $\left(T_{1}=0 \mathrm{~K}\right.$, and $T_{2}=T_{*}$.

Replacing $T=T_{S}$ and $\rho=\rho_{S}$ in relation (14) and integrating the function $F_{\rho}(T)$ by using the Simpson's method with condensation of nodes towards the left end, the density ratio can be obtained. 
The ratios of pressures, speed of sound and the sections corresponding to $M=M_{S}$ can be calculated respectively by using the relations (15), (22) and (19) by replacing $T=T_{S}, \rho=\rho_{S}$, $P=P_{S}, a=a_{S}$ and $A=A_{S}$.

The integration results of the ratios $\rho_{*} / \rho_{0}, \rho_{S} / \rho_{0}$ and $A_{S} / A_{*}$ primarily depend on the values of $N, b_{1}$ and $b_{2}$.

\subsection{Supersonic nozzle conception}

For supersonic nozzle application, it is necessary to determine the thrust coefficient. For nozzles giving a uniform and parallel flow at the exit section, the thrust coefficient is (Peterson \& Hill, 1965 \& Zebbiche, Youbi, 2005b)

$$
C_{F}=\frac{F}{P_{0} A_{*}}
$$

Where

$$
F=m V_{E}=m M_{E} a_{E}
$$

The introduction of relations (21), (22) into (32) gives as the following relation:

$$
C_{F}=\gamma\left(T_{0}\right) M_{E}\left(\frac{a_{E}}{a_{0}}\right)\left(\frac{\rho_{*}}{\rho_{*}}\right)\left(\frac{a_{*}}{a_{0}}\right)
$$

The design of the nozzle is made on the basis of its application. For rockets and missiles applications, the design is made to obtain nozzles having largest possible exit Mach number, which gives largest thrust coefficient, and smallest possible length, which give smallest possible mass of structure.

For the application of blowers, we make the design on the basis to obtain the smallest possible temperature at the exit section, to not to destroy the measuring instruments, and to save the ambient conditions. Another condition requested is to have possible largest ray of the exit section for the site of instruments. Between the two possibilities of construction, we prefer the first one.

\subsection{Error of perfect gas model}

The mathematical perfect gas model is developed on the basis to regarding the specific heat $C_{P}$ and ratio $\gamma$ as constants, which gives acceptable results for low temperature. According to this study, we can notice a difference on the given results between the perfect gas model and developed here model.The error given by the PG model compared to our HT model can be calculated for each parameter. Then, for each value $\left(T_{0}, M\right)$, the $\varepsilon$ error can be evaluated by the following relationship:

$$
\varepsilon_{y}\left(T_{0}, M\right)=\left|1-\frac{y_{P G}\left(T_{0}, M\right)}{y_{H T}\left(T_{0}, M\right)}\right| \times 100
$$

The letter $y$ in the expression (35) can represent all above-mentioned parameters. As a rule for the aerodynamic applications, the error should be lower than $5 \%$. 


\section{Application}

The design of a supersonic propulsion nozzle can be considered as example. The use of the obtained dimensioned nozzle shape based on the application of the PG model given a supersonic uniform Mach number $M_{S}$ at the exit section of rockets, degrades the desired performances (exit Mach number, pressure force), especially if the temperature $T_{0}$ of the combustion chamber is higher. We recall here that the form of the nozzle structure does not change, except the thermodynamic behaviour of the air which changes with $T_{0}$. Two situations can be presented.

The first situation presented is that, if we wants to preserve the same variation of the Mach number throughout the nozzle, and consequently, the same exit Mach number $M_{E}$, is necessary to determine by the application of our model, the ray of each section and in particular the ray of the exit section, which will give the same variation of the Mach number, and consequently another shape of the nozzle will be obtained.

$$
\begin{gathered}
M_{S}(H T)=M_{S}(P G) \\
M_{S}(P G)=\frac{\sqrt{2 H\left[T_{S(H T)}\right]}}{a\left[T_{S(H T)}\right]} \\
\frac{A_{S}}{A_{*}}(H T)=e^{\int_{T_{S}(H T)}^{T_{*}} F_{A}(T) d T}>\frac{A_{S}}{A_{*}}(P G)
\end{gathered}
$$

The relation (36) indicates that the Mach number of the $P G$ model is preserved for each section in our calculation. Initially, we determine the temperature at each section; witch presents the solution of equation (37). To determine the ratio of the sections, we use the relation (38). The ratio of the section obtained by our model will be superior that that determined by the $P G$ model as present equation (38). Then the shape of the nozzle obtained by $P G$ model is included in the nozzle obtained by our model. The temperature $T_{0}$ presented in equation (38) is that correspond to the temperature $T_{0}$ for our model.

The second situation consists to preserving the shape of the nozzle dimensioned on the basis of PG model for the aeronautical applications considered the HT model.

$$
\begin{aligned}
& \frac{A_{S}}{A_{*}}(H T)=\frac{A_{S}}{A_{*}}(P G) \\
& M_{S}(H T)<M_{S}(P G)
\end{aligned}
$$

The relation (39) presents this situation. In this case, the nozzle will deliver a Mach number lower than desired, as shows the relation (40). The correction of the Mach number for HT model is initially made by the determination of the temperature $T_{S}$ as solution of equation (38), then determine the exit Mach number as solution of relation (37). The resolution of equation (38) is done by combining the dichotomy method with Simpson's algorithm. 


\section{Results and comments}

Figures 4 and 5 respectively represent the variation of specific heat $C_{P}(T)$ and the ratio $\gamma(T)$ of the air versus the temperature up to $3550 \mathrm{~K}$ for HT and PG models. The graphs at high temperature are presented by using the polynomial interpolation (23). We can say that at low temperature until approximately $240 \mathrm{~K}$, the gas can be regarded as calorically perfect, because of the invariance of specific heat $C_{P}(T)$ and the ratio $\gamma(T)$. But if $T_{0}$ increases, we can see the difference between these values and it influences on the thermodynamic parameters of the flow.

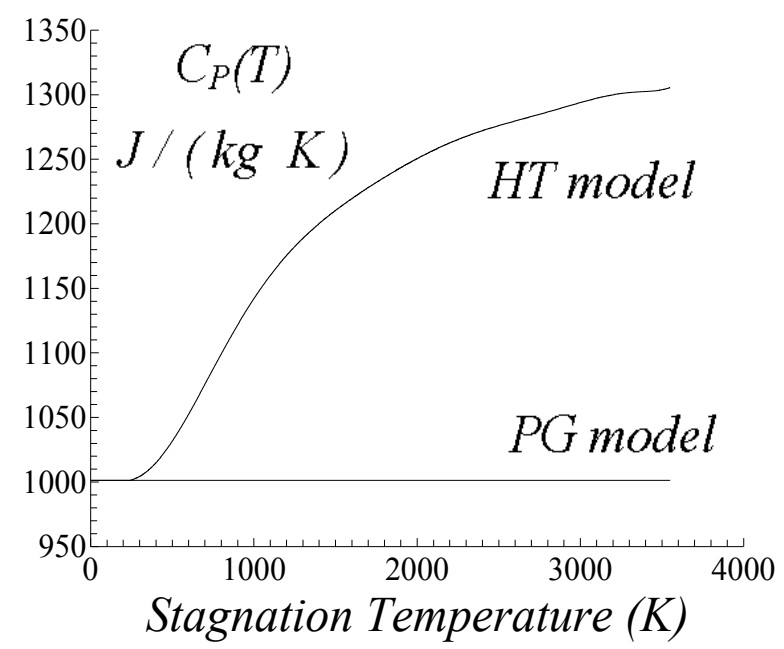

Fig. 4. Variation of the specific heat for constant pressure versus stagnation temperature $T_{0}$.

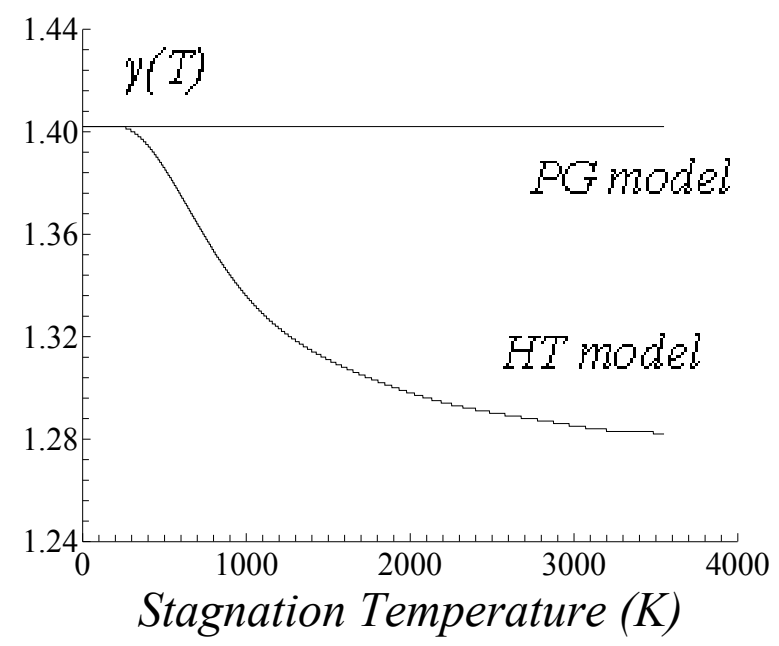

Fig. 5. Variation of the specific heats ratio versus $T_{0}$. 


\subsection{Results for the critical parameters}

Figures 6, 7 and 8 represent the variation of the critical thermodynamic ratios versus $T_{0}$. It can be seen that with enhancement $T_{0}$, the critical parameters vary, and this variation becomes considerable for high values of $T_{0}$ unlike to the $P G$ model, where they do not depend on $T_{0}$. For example, the value of the temperature ratio given by the HT model is always higher than the value given by the $P G$ model. The ratios are determined by the choice of $N=300000, b_{1}=0.1$ and $b_{2}=2.0$ to have a precision better than $\varepsilon=10-5$. The obtained numerical values of the critical parameters are presented in the table 3.

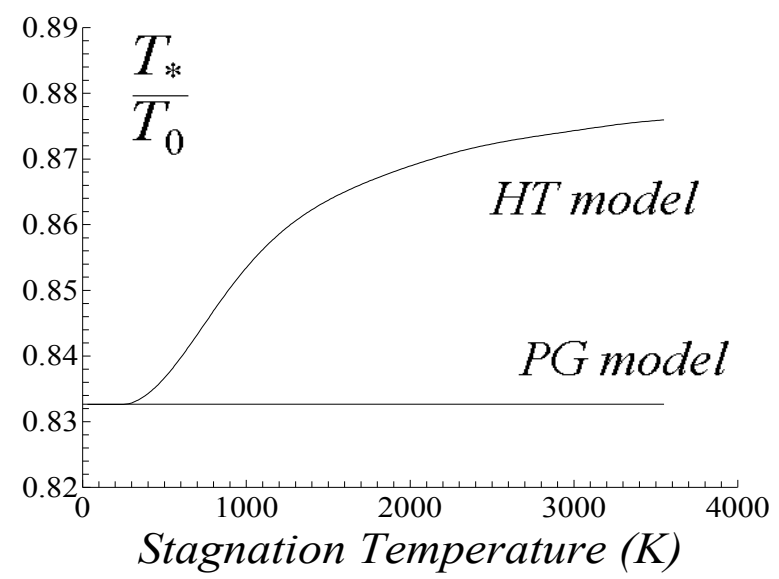

Fig. 6. Variation of $T_{*} / T_{0}$ versus $T_{0}$.

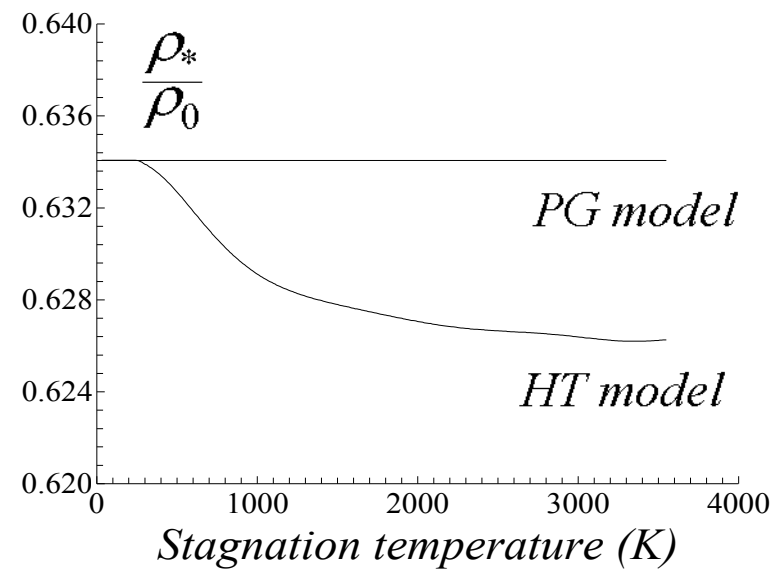

Fig. 7. Variation of $\rho * / \rho_{0}$ versus $T_{0}$. 


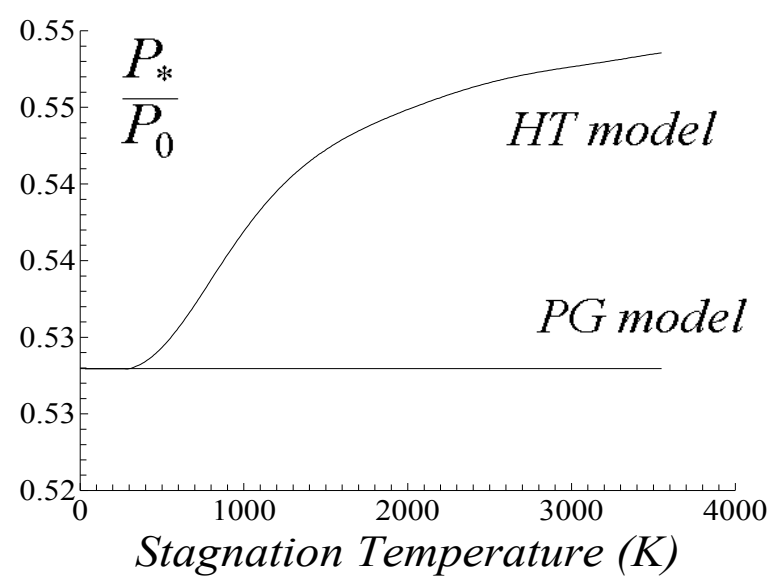

Fig. 8. Variation of $P_{*} / P_{0}$ versus $T_{0}$.

Figure 9 shows that mass flow rate through the critical cross section given by the perfect gas theory is lower than it is at the HT model, especially for values of $T_{0}$.

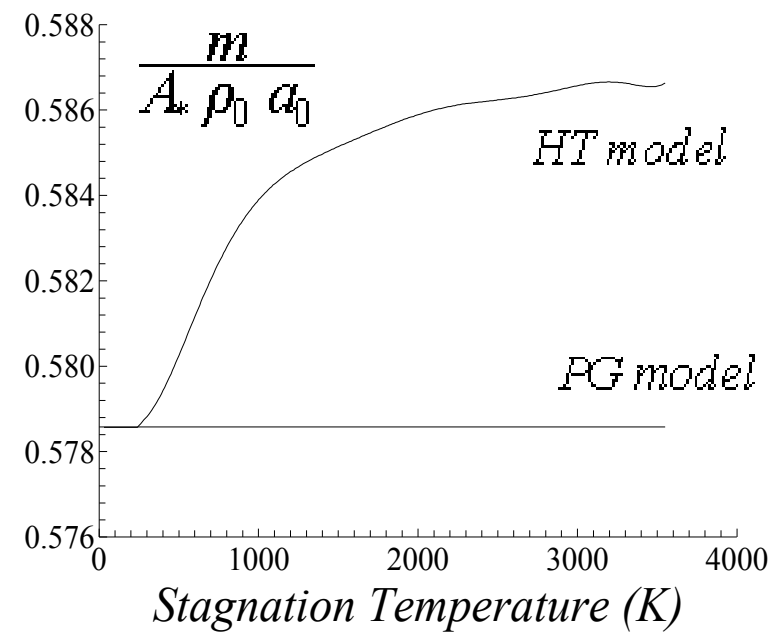

Fig. 9. Variation of the non-dimensional critical mass flow rate with $T_{0}$. 
Figure 10 presents the variation of the critical sound velocity ratio versus $T_{0}$. The influence of the $T_{0}$ on this parameter can be found.

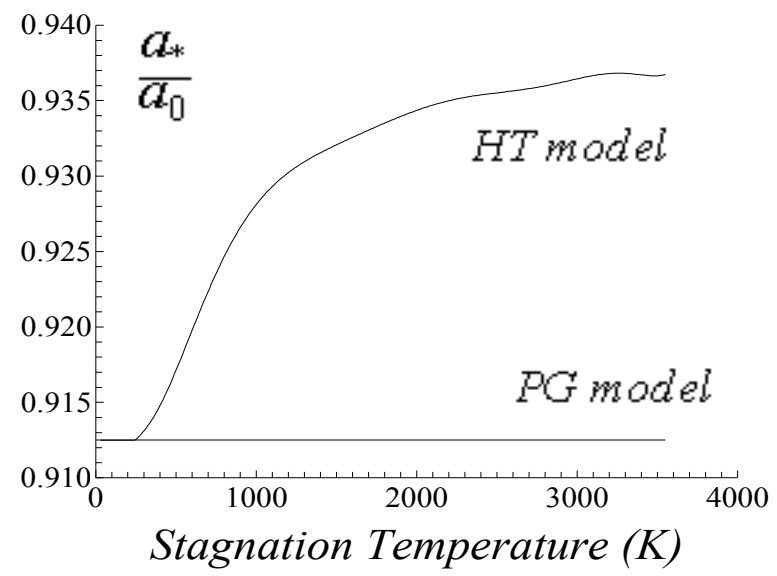

Fig. 10. Effect of $T_{0}$ on the velocity sound ratio.

\begin{tabular}{|cccccc|}
\hline & $\frac{T_{*}}{T_{0}}$ & $\frac{P_{*}}{P_{0}}$ & $\frac{\rho_{*}}{\rho_{0}}$ & $\frac{a_{*}}{a_{0}}$ & $\frac{m}{A_{*} \rho_{0} a_{0}}$ \\
\hline $\mathrm{PG}(\gamma=1.402)$ & 0.8326 & 0.5279 & 0.6340 & 0.9124 & 0.5785 \\
\hline $\mathrm{T}_{0}=298.15 \mathrm{~K}$ & 0.8328 & 0.5279 & 0.6339 & 0.9131 & 0.5788 \\
\hline $\mathrm{T}_{0}=500 \mathrm{~K}$ & 0.8366 & 0.5293 & 0.6326 & 0.9171 & 0.5802 \\
\hline $\mathrm{T}_{0}=1000 \mathrm{~K}$ & 0.8535 & 0.5369 & 0.6291 & 0.9280 & 0.5838 \\
\hline $\mathrm{T}_{0}=2000 \mathrm{~K}$ & 0.8689 & 0.5448 & 0.6270 & 0.9343 & 0.5858 \\
\hline $\mathrm{T}_{0}=2500 \mathrm{~K}$ & 0.8722 & 0.5466 & 0.6266 & 0.9355 & 0.5862 \\
\hline $\mathrm{T}_{0}=3000 \mathrm{~K}$ & 0.8743 & 0.5475 & 0.6263 & 0.9365 & 0.5865 \\
\hline $\mathrm{T}_{0}=3500 \mathrm{~K}$ & 0.8758 & 0.5484 & 0.6262 & 0.9366 & 0.5865 \\
\hline
\end{tabular}

Table 3. Numerical values of the critical parameters at high temperature.

\subsection{Results for the supersonic parameters}

Figures 11, 12 and 13 presents the variation of the supersonic flow parameters in a crosssection versus Mach number for $T_{0}=1000 \mathrm{~K}, 2000 \mathrm{~K}$ and $3000 \mathrm{~K}$, including the case of perfect gas for $\gamma=1.402$. When $M=1$, we can obtain the values of the critical ratios. If we take into account the variation of $C_{P}(T)$, the temperature $T_{0}$ influences on the value of the thermodynamic and geometrical parameters of flow unlike the $P G$ model.

The curve 4 of figure 11 is under the curves of the HT model, which indicates that the perfect gas model cool the flow compared to the real thermodynamic behaviour of the gas, and consequently, it influences on the dimensionless parameters of a nozzle. At low temperature and Mach number, the theory of perfect gas gives acceptable results. The obtained numerical values of the supersonic flow parameters, the cross section area ratio and sound velocity ratio are presented respectively if the tables 4, 5, 6, 7 and 8 . 


\begin{tabular}{|cccccc|}
\hline $\mathrm{T} / \mathrm{T}_{0}$ & $M=2.00$ & $M=3.00$ & $M=4.00$ & $M=5.00$ & $M=6.00$ \\
\hline$P G(\gamma=1.402)$ & 0.5543 & 0.3560 & 0.2371 & 0.1659 & 0.1214 \\
\hline$T_{0}=298.15 \mathrm{~K}$ & 0.5544 & 0.3560 & 0.2372 & 0.1659 & 0.1214 \\
\hline$T_{0}=500 \mathrm{~K}$ & 0.5577 & 0.3581 & 0.2386 & 0.1669 & 0.1221 \\
\hline$T_{0}=1000 \mathrm{~K}$ & 0.5810 & 0.3731 & 0.2481 & 0.1736 & 0.1269 \\
\hline$T_{0}=1500 \mathrm{~K}$ & 0.6031 & 0.3911 & 0.2594 & 0.1810 & 0.1323 \\
\hline$T_{0}=2000 \mathrm{~K}$ & 0.6163 & 0.4058 & 0.2694 & 0.1873 & 0.1366 \\
\hline$T_{0}=2500 \mathrm{~K}$ & 0.6245 & 0.4162 & 0.2778 & 0.1928 & 0.1403 \\
\hline$T_{0}=3000 \mathrm{~K}$ & 0.6301 & 0.4233 & 0.2848 & 0.1977 & 0.1473 \\
\hline$T_{0}=3500 \mathrm{~K}$ & 0.6340 & 0.4285 & 0.2901 & 0.2018 & 0.1462 \\
\hline
\end{tabular}

Table 4 . Numerical values of the temperature ratio at high temperature

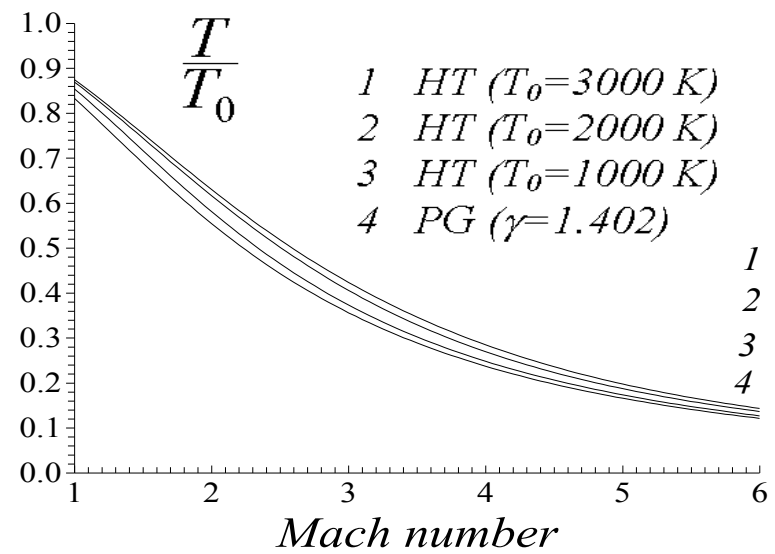

Fig. 11. Variation of $T / T_{0}$ versus Mach number.

\begin{tabular}{|cccccc|}
\hline$\rho / \rho_{0}$ & $M=2.00$ & $M=3.00$ & $M=4.00$ & $M=5.00$ & $M=6.00$ \\
\hline$P G(\gamma=1.402)$ & 0.2304 & 0.0765 & 0.0278 & 0.0114 & 0.0052 \\
\hline$T_{0}=298.15 \mathrm{~K}$ & 0.2304 & 0.0765 & 0.0278 & 0.0114 & 0.0052 \\
\hline$T_{0}=500 \mathrm{~K}$ & 0.2283 & 0.0758 & 0.0276 & 0.0113 & 0.0052 \\
\hline$T_{0}=1000 \mathrm{~K}$ & 0.2181 & 0.0696 & 0.0250 & 0.0103 & 0.0047 \\
\hline$T_{0}=1500 \mathrm{~K}$ & 0.2116 & 0.0636 & 0.0220 & 0.0089 & 0.0041 \\
\hline$T_{0}=2000 \mathrm{~K}$ & 0.2087 & 0.0601 & 0.0197 & 0.0077 & 0.0035 \\
\hline$T_{0}=2500 \mathrm{~K}$ & 0.2069 & 0.0581 & 0.0182 & 0.0069 & 0.0030 \\
\hline$T_{0}=3000 \mathrm{~K}$ & 0.2057 & 0.0569 & 0.0173 & 0.0063 & 0.0027 \\
\hline$T_{0}=3500 \mathrm{~K}$ & 0.2049 & 0.0560 & 0.0166 & 0.0058 & 0.0024 \\
\hline
\end{tabular}

Table 5. Numerical values of the density ratio at high temperature 


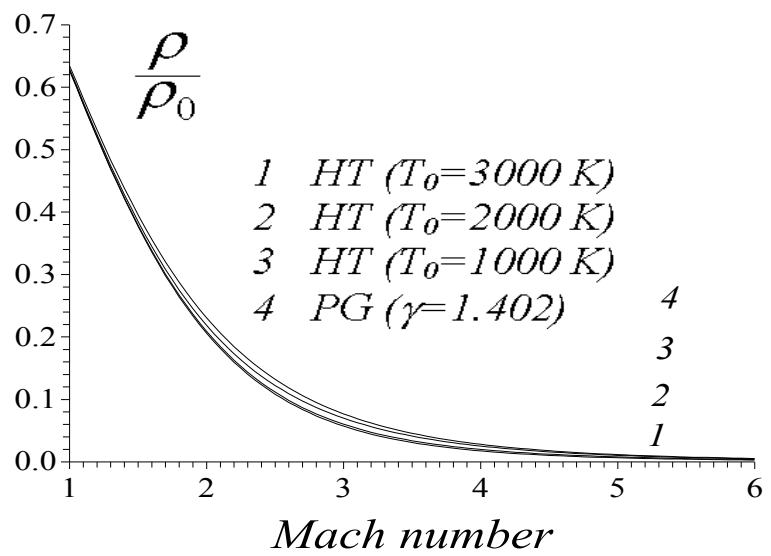

Fig. 12. Variation of $\rho / \rho_{0}$ versus Mach number.

\begin{tabular}{|cccccc|}
\hline$P / P_{0}$ & $M=2.00$ & $M=3.00$ & $M=4.00$ & $M=5.00$ & $M=6.00$ \\
\hline$P G(\gamma=1.402)$ & 0.1277 & 0.0272 & 0.0066 & 0.0019 & 0.0006 \\
\hline$T_{0}=298.15 \mathrm{~K}$ & 0.1277 & 0.0272 & 0.0066 & 0.0019 & 0.0006 \\
\hline$T_{0}=500 \mathrm{~K}$ & 0.1273 & 0.0271 & 0.0065 & 0.0018 & 0.0006 \\
\hline$T_{0}=1000 \mathrm{~K}$ & 0.1267 & 0.0259 & 0.0062 & 0.0017 & 0.0006 \\
\hline$T_{0}=1500 \mathrm{~K}$ & 0.1276 & 0.0248 & 0.0057 & 0.0016 & 0.0005 \\
\hline$T_{0}=2000 \mathrm{~K}$ & 0.1286 & 0.0244 & 0.0053 & 0.0014 & 0.0004 \\
\hline$T_{0}=2500 \mathrm{~K}$ & 0.1292 & 0.0242 & 0.0050 & 0.0013 & 0.0004 \\
\hline$T_{0}=3000 \mathrm{~K}$ & 0.1296 & 0.0240 & 0.0049 & 0.0004 & 0.0003 \\
\hline$T_{0}=3500 \mathrm{~K}$ & 0.1299 & 0.0240 & 0.0048 & 0.0011 & 0.0003 \\
\hline
\end{tabular}

Table 6. Numerical values of the Pressure ratio at high temperature.

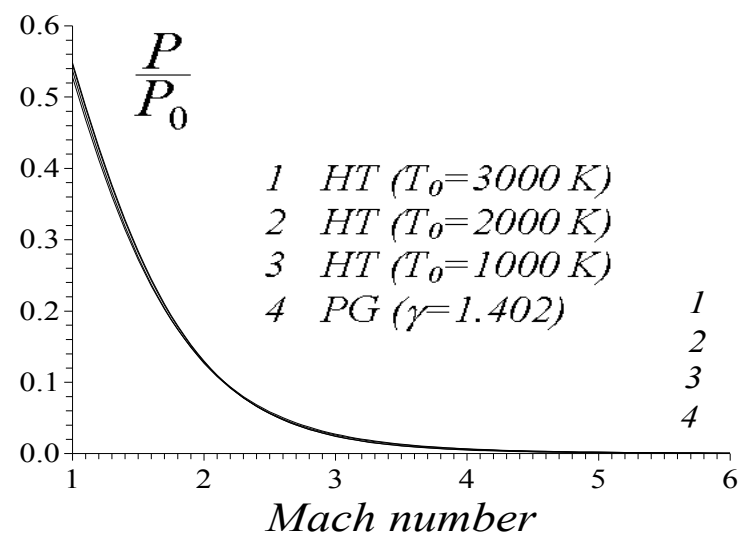

Fig. 13. Variation of $P / P_{0}$ versus Mach number. 


\begin{tabular}{|cccccc|}
\hline$A / A^{*}$ & $M=2.00$ & $M=3.00$ & $M=4.00$ & $M=5.00$ & $M=6.00$ \\
\hline$P G(\gamma=1.402)$ & 1.6859 & 4.2200 & 10.6470 & 24.7491 & 52.4769 \\
\hline$T_{0}=298.15 \mathrm{~K}$ & 1.6859 & 4.2195 & 10.6444 & 24.7401 & 52.4516 \\
\hline$T_{0}=500 \mathrm{~K}$ & 1.6916 & 4.2373 & 10.6895 & 24.8447 & 52.6735 \\
\hline$T_{0}=1000 \mathrm{~K}$ & 1.7295 & 4.4739 & 11.3996 & 26.5019 & 56.1887 \\
\hline$T_{0}=1500 \mathrm{~K}$ & 1.7582 & 4.7822 & 12.6397 & 29.7769 & 63.2133 \\
\hline$T_{0}=2000 \mathrm{~K}$ & 1.7711 & 4.9930 & 13.8617 & 33.5860 & 72.0795 \\
\hline$T_{0}=2500 \mathrm{~K}$ & 1.7795 & 5.1217 & 14.8227 & 37.2104 & 81.2941 \\
\hline$T_{0}=3000 \mathrm{~K}$ & 1.7851 & 5.2091 & 15.5040 & 40.3844 & 90.4168 \\
\hline$T_{0}=3500 \mathrm{~K}$ & 1.7889 & 5.2727 & 16.0098 & 43.0001 & 98.7953 \\
\hline
\end{tabular}

Table 7. Numerical Values of the cross section area ratio at high temperature.

Figure 14 represent the variation of the critical cross-section area section ratio versus Mach number at high temperature. For low values of Mach number and $T_{0}$, the four curves fuses and start to be differs when $M>2.00$. We can see that the curves 3 and 4 are almost superposed for any value of $T_{0}$. This result shows that the $P G$ model can be used for $T_{0}<1000 \mathrm{~K}$.

Figure 15 presents the variation of the sound velocity ratio versus Mach number at high temperature. $T_{0}$ value influences on this parameter.

Figure 16 shows the variation of the thrust coefficient versus exit Mach number for various values of $T_{0}$. It can be seen the effect of $T_{0}$ on this parameter. We can found that all the four curves are almost confounded when $M_{E}<2.00$ approximately. After this value, the curves begin to separates progressively. The numerical values of the thrust coefficient are presented in the table 9.

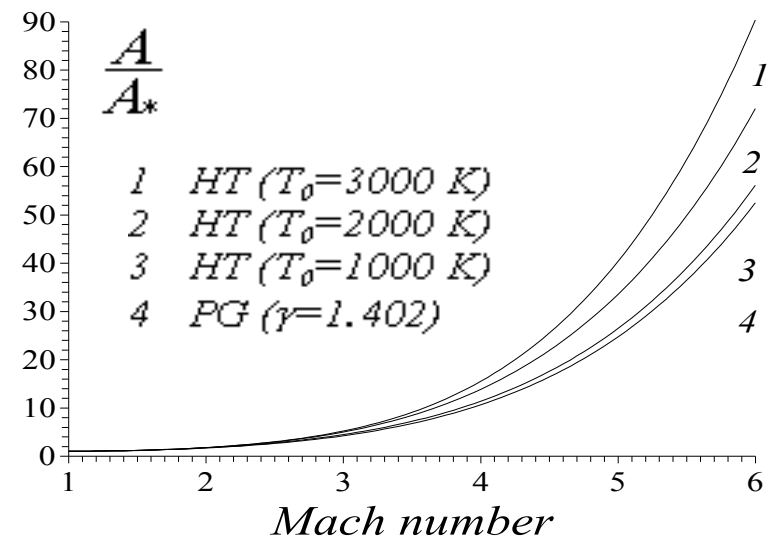

Fig. 14. Variation of the critical cross-section area ratio versus Mach number. 


\begin{tabular}{|cccccc|}
\hline$a / a_{0}$ & $M=2.00$ & $M=3.00$ & $M=4.00$ & $M=5.00$ & $M=6.00$ \\
\hline$P G(\gamma=1.402)$ & 0.7445 & 0.5966 & 0.4870 & 0.4074 & 0.3484 \\
\hline$T_{0}=298.15 \mathrm{~K}$ & 0.7450 & 0.5970 & 0.4873 & 0.4076 & 0.3486 \\
\hline$T_{0}=500 \mathrm{~K}$ & 0.7510 & 0.6019 & 0.4913 & 0.4110 & 0.3515 \\
\hline$T_{0}=1000 \mathrm{~K}$ & 0.7739 & 0.6245 & 0.5103 & 0.4268 & 0.3651 \\
\hline$T_{0}=1500 \mathrm{~K}$ & 0.7862 & 0.6408 & 0.5254 & 0.4398 & 0.3762 \\
\hline$T_{0}=2000 \mathrm{~K}$ & 0.7923 & 0.6501 & 0.5354 & 0.4489 & 0.3841 \\
\hline$T_{0}=2500 \mathrm{~K}$ & 0.7959 & 0.6556 & 0.5420 & 0.4553 & 0.3898 \\
\hline$T_{0}=3000 \mathrm{~K}$ & 0.7985 & 0.6595 & 0.5465 & 0.4600 & 0.3942 \\
\hline$T_{0}=3500 \mathrm{~K}$ & 0.7998 & 0.6618 & 0.5495 & 0.4632 & 0.3973 \\
\hline
\end{tabular}

Table 8 . Numerical values of the sound velocity ratio at high temperature.

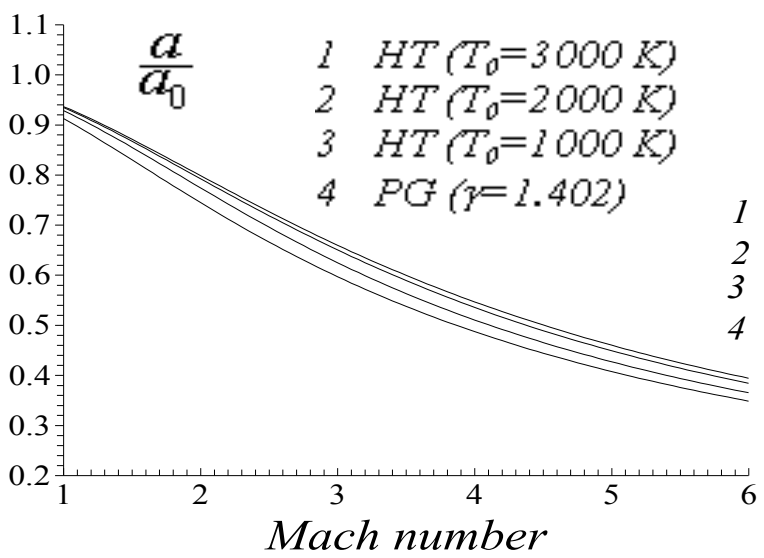

Fig. 15. Variation of the ratio of the velocity sound versus Mach number. 


\begin{tabular}{|cccccc|}
\hline$C_{F}$ & $M=2.00$ & $M=3.00$ & $M=4.00$ & $M=5.00$ & $M=6.00$ \\
\hline$P G(\gamma=1.402)$ & 1.2078 & 1.4519 & 1.5802 & 1.6523 & 1.6959 \\
\hline$T_{0}=298.15 \mathrm{~K}$ & 1.2078 & 1.4518 & 1.5800 & 1.6521 & 1.6957 \\
\hline$T_{0}=500 \mathrm{~K}$ & 1.2076 & 1.4519 & 1.5802 & 1.6523 & 1.6958 \\
\hline$T_{0}=1000 \mathrm{~K}$ & 1.2072 & 1.4613 & 1.5919 & 1.6646 & 1.7085 \\
\hline$T_{0}=1500 \mathrm{~K}$ & 1.2062 & 1.4748 & 1.6123 & 1.6871 & 1.7317 \\
\hline$T_{0}=2000 \mathrm{~K}$ & 1.2048 & 1.4832 & 1.6288 & 1.7069 & 1.7527 \\
\hline$T_{0}=2500 \mathrm{~K}$ & 1.2042 & 1.4879 & 1.6401 & 1.7221 & 1.7694 \\
\hline$T_{0}=3000 \mathrm{~K}$ & 1.2038 & 1.4912 & 1.6479 & 1.7337 & 1.7828 \\
\hline$T_{0}=3500 \mathrm{~K}$ & 1.2033 & 1.4936 & 1.6533 & 1.7422 & 1.7932 \\
\hline
\end{tabular}

Table 9. Numerical values of the thrust coefficient at high temperature

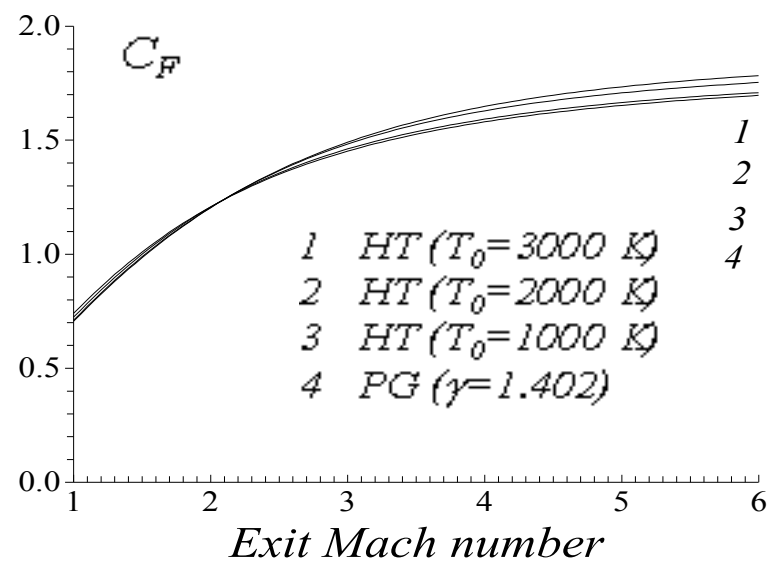

Fig. 16. Variation of $C_{F}$ versus exit Mach number.

\subsection{Results for the error given by the perfect gas model}

Figure 17 presents the relative error of the thermodynamic and geometrical parameters between the $P G$ and the HT models for several $T_{0}$ values.

It can be seen that the error depends on the values of $T_{0}$ and $M$. For example, if $T_{0}=2000 \mathrm{~K}$ and $M=3.00$, the use of the $P G$ model will give a relative error equal to $\varepsilon=14.27 \%$ for the temperatures ratio, $\varepsilon=27.30 \%$ for the density ratio, error $\varepsilon=15.48 \%$ for the critical sections ratio and $\varepsilon=2.11 \%$ for the thrust coefficient. For lower values of $M$ and $T_{0}$, the error $\varepsilon$ is weak. The curve 3 in the figure 17 is under the error $5 \%$ independently of the Mach number, which is interpreted by the use potential of the PG model when $T_{0}<1000 \mathrm{~K}$.

We can deduce for the error given by the thrust coefficient that it is equal to $\varepsilon=0.0 \%$, if $M_{E}=2.00$ approximately independently of $T_{0}$. There is no intersection of the three curves in the same time. When $M_{E}=2.00$. 

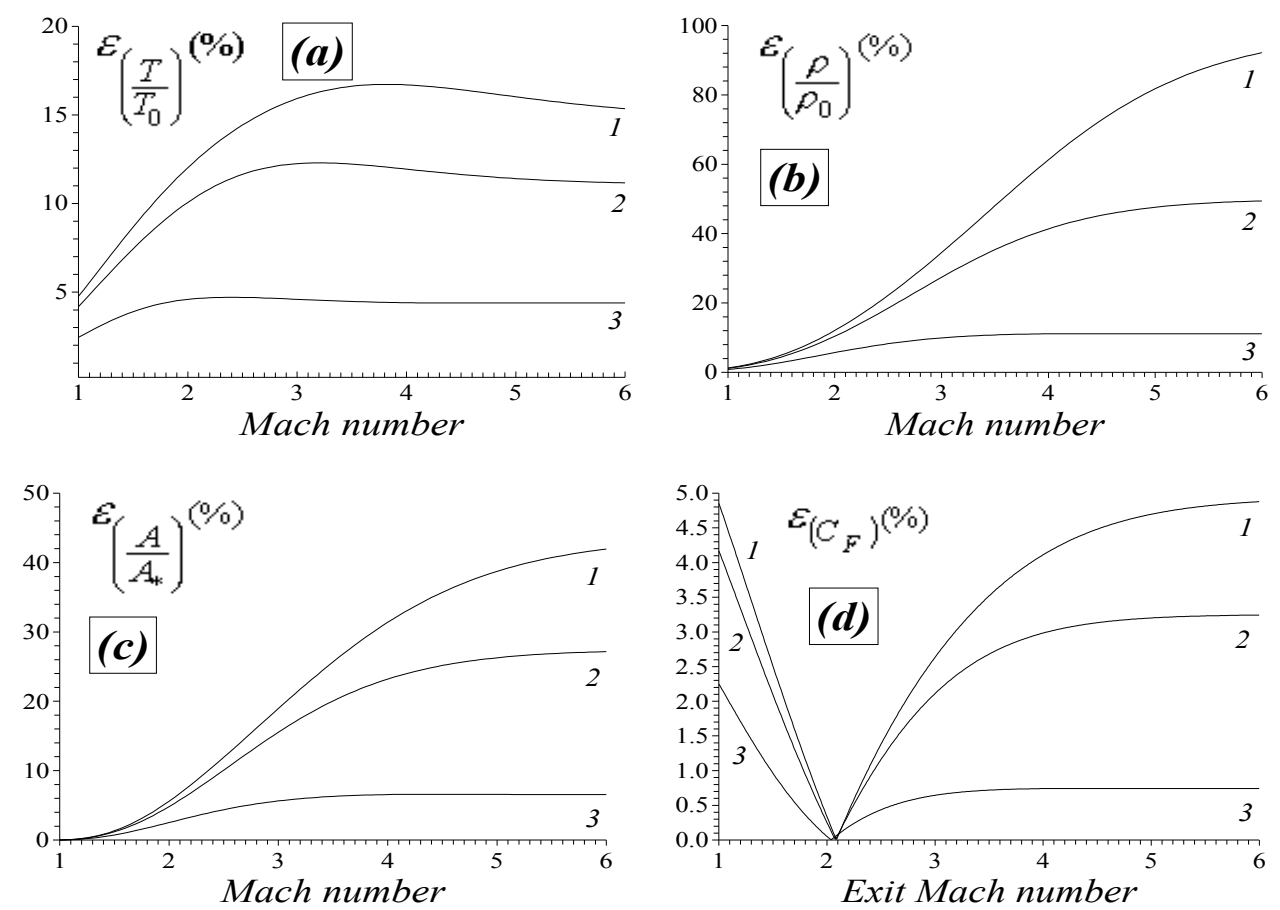

Curve 1 Error compared to HT model for $\left(\mathrm{T}_{0}=3000 \mathrm{~K}\right)$

Curve 2 Error compared to HT model for $\left(\mathrm{T}_{0}=2000 \mathrm{~K}\right)$

Curve $3 \quad$ Error compared to HT model for $\left(\mathrm{T}_{0}=1000 \mathrm{~K}\right)$

(a): Temperature ratio. (b): Density ratio. (c): Critical sections ratio. (d): Thrust coefficient.

Fig. 17. Variation of the relative error given by supersonic parameters of $P G$ versus Mach number.

\subsection{Results for the supersonic nozzle application}

Figure 18 presents the variation of the Mach number through the nozzle for $T_{0}=1000 \mathrm{~K}, 2000$ $\mathrm{K}$ and $3000 \mathrm{~K}$, including the case of perfect gas presented by curve 4 . The example is selected for $M_{S}=3.00$ for the $P G$ model. If $T_{0}$ is taken into account, we will see a fall in Mach number of the dimensioned nozzle in comparison with the $P G$ model. The more is the temperature $T_{0}$, the more it is this fall. Consequently, the thermodynamics parameters force to design the nozzle with different dimensions than it is predicted by use the $P G$ model. It should be noticed that the difference becomes considerable if the value $T_{0}$ exceeds $1000 \mathrm{~K}$.

Figure 19 present the correction of the Mach number of nozzle giving exit Mach number $M_{S}$, dimensioned on the basis of the $P G$ model for various values of $T_{0}$.

One can see that the curves confound until Mach number $M_{S}=2.0$ for the whole range of $T_{0}$. From this value, the difference between the three curves 1, 2 and 3, start to increase. The curves 3 and 4 are almost confounded whatever the Mach number if the value of $T_{0}$ is lower than $1000 \mathrm{~K}$. For example, if the nozzle delivers a Mach number $M_{S}=3.00$ at the exit section, on the assumption of the PG model, the HT model gives Mach number equal to $M_{S}=2.93$, 2.84 and 2.81 for $T_{0}=1000 \mathrm{~K}, 2000 \mathrm{~K}$ and $3000 \mathrm{~K}$ respectively. The numerical values of the correction of the exit Mach number of the nozzle are presented in the table 10. 

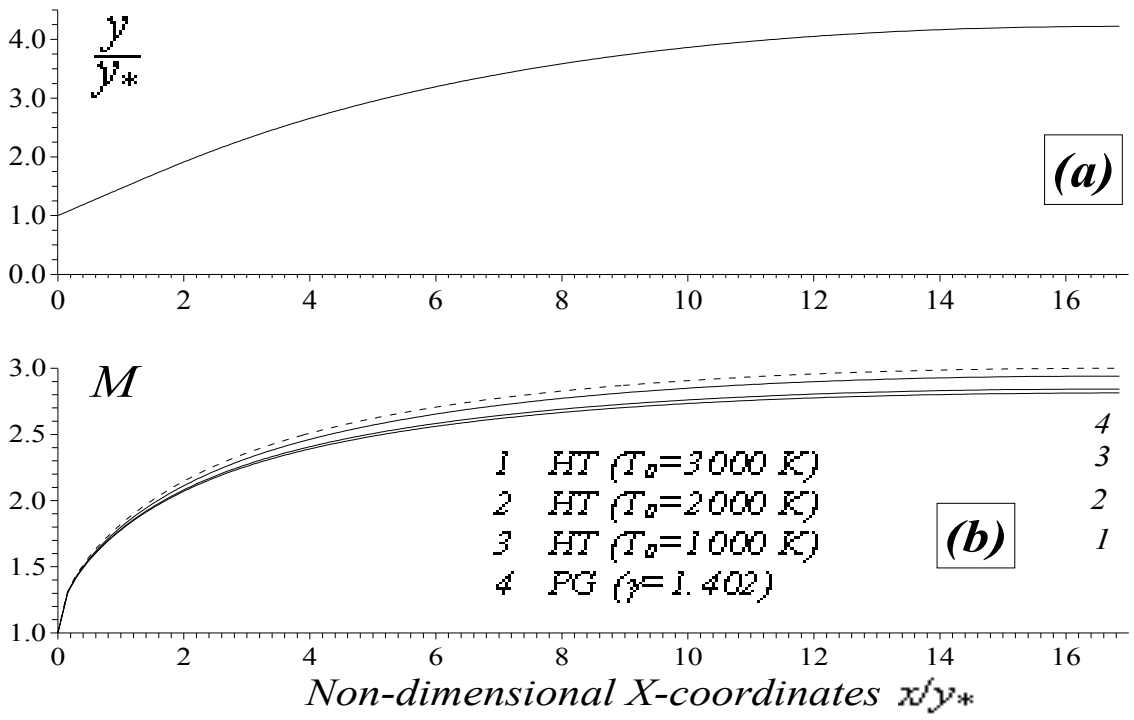

(a): Shape of nozzle, dimensioned on the consideration of the PG model for $M_{S}=3.00$.

(b): Variation of the Mach number at high temperature through the nozzle.

Fig. 18. Effect of stagnation temperature on the variation of the Mach number through the nozzle.

\begin{tabular}{|ccccccc|}
\hline$M_{S}(P G r=1.402)$ & 1.5000 & 2.0000 & 3.0000 & 4.0000 & 5.0000 & 6.0000 \\
\hline$M_{S}\left(T_{0}=298.15 \mathrm{~K}\right)$ & 1.4995 & 1.9995 & 2.9995 & 3.9993 & 4.9989 & 5.9985 \\
\hline$M_{S}\left(T_{0}=500 \mathrm{~K}\right)$ & 1.4977 & 1.9959 & 2.9956 & 3.9955 & 4.9951 & 5.9947 \\
\hline$M_{S}\left(T_{0}=1000 \mathrm{~K}\right)$ & 1.4879 & 1.9705 & 2.9398 & 3.9237 & 4.9145 & 5.9040 \\
\hline$M_{S}\left(T_{0}=1500 \mathrm{~K}\right)$ & 1.4830 & 1.9534 & 2.8777 & 3.8147 & 4.7727 & 5.7411 \\
\hline$M_{S}\left(T_{0}=2000 \mathrm{~K}\right)$ & 1.4807 & 1.9463 & 2.8432 & 3.7293 & 4.6372 & 5.5675 \\
\hline$M_{S}\left(T_{0}=2500 \mathrm{~K}\right)$ & 1.4792 & 1.9417 & 2.8245 & 3.6765 & 4.5360 & 5.4209 \\
\hline$M_{S}\left(T_{0}=3000 \mathrm{~K}\right)$ & 1.4785 & 1.9388 & 2.8121 & 3.6454 & 4.4676 & 5.3066 \\
\hline$M_{S}\left(T_{0}=3500 \mathrm{~K}\right)$ & 1.4778 & 1.9368 & 2.8035 & 3.6241 & 4.4216 & 5.2237 \\
\hline
\end{tabular}

Table 10. Correction of the exit Mach number of the nozzle.

Figure 20 presents the supersonic nozzles shapes delivering a same variation of the Mach number throughout the nozzle and consequently given the same exit Mach number $M_{S}=3.00$. The variation of the Mach number through these 4 nozzles is illustrated on curve 4 of figure 18. The three other curves 1, 2, and, 3 of figure 15 are obtained with the HT model use for $T_{0}=3000 \mathrm{~K}, 2000 \mathrm{~K}$ and $1000 \mathrm{~K}$ respectively. The curve 4 of figure 20 is the same as it is in the figure $13 \mathrm{a}$, and it is calculated with the $P G$ model use. The nozzle that is calculated according to the $P G$ model provides less cross-section area in comparison with the HT model. 


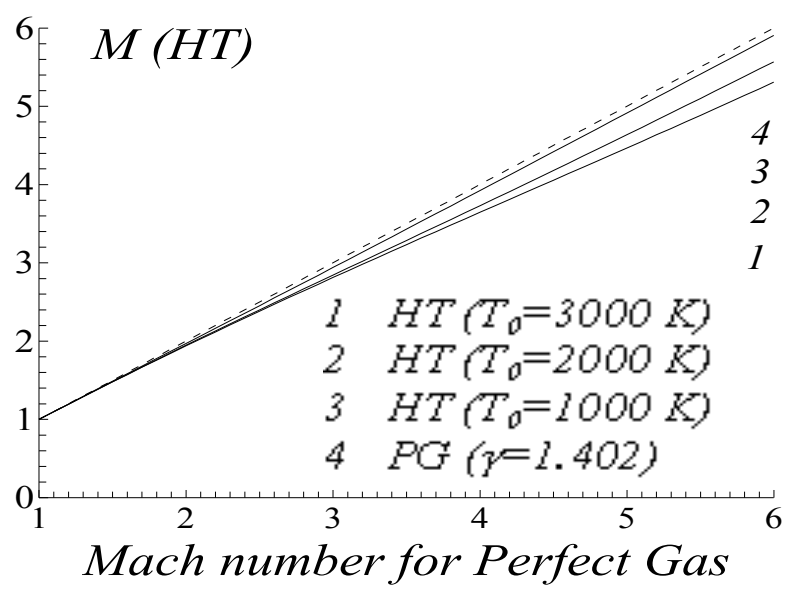

Fig. 19. Correction of the Mach number at High Temperature of a nozzle dimensioned on the perfect gas model.

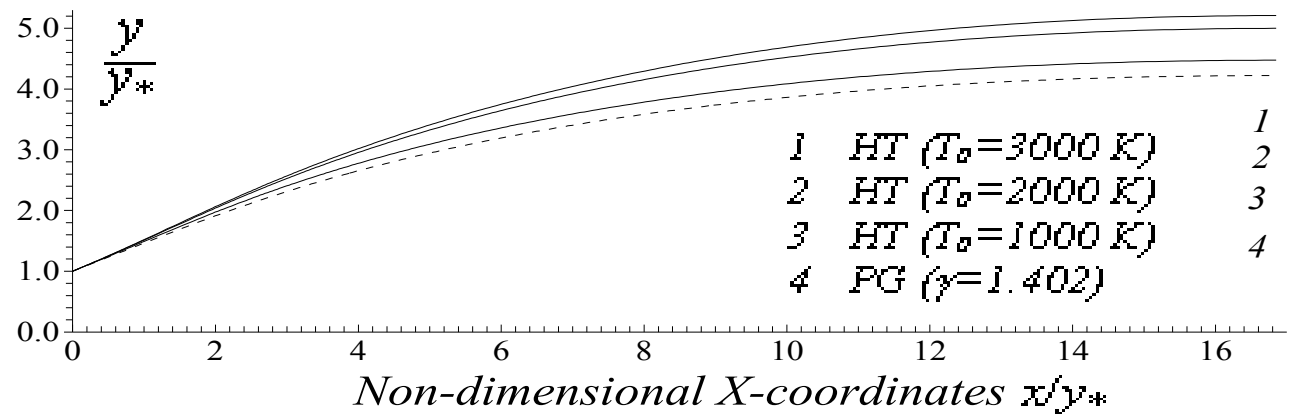

Fig. 20. Shapes of nozzles at high temperature corresponding to same Mach number variation througout the nozzle and given $M_{S}=3.00$ at the exit.

\section{Conclusion}

From this study, we can quote the following points:

If we accept an error lower than $5 \%$, we can study a supersonic flow using a perfect gas relations, if the stagnation temperature $T_{0}$ is lower than $1000 \mathrm{~K}$ for any value of Mach number, or when the Mach number is lower than 2.0 for any value of $T_{0}$ up to approximately $3000 \mathrm{~K}$.

The $P G$ model is represented by an explicit and simple relations, and do not request a high time to make calculation, unlike the proposed model, which requires the resolution of a nonlinear algebraic equations, and integration of two complex analytical functions. It takes more time for calculation and for data processing.

The basic variable for our model is the temperature and for the PG model is the Mach number because of a nonlinear implicit equation connecting the parameters $T$ and $M$. 
The relations presented in this study are valid for any interpolation chosen for the function $C_{P}(T)$. The essential one is that the selected interpolation gives small error.

We can choose another substance instead of the air. The relations remain valid, except that it is necessary to have the table of variation of $C_{P}$ and $\gamma$ according to the temperature and to make a suitable interpolation.

The cross section area ratio presented by the relation (19) can be used as a source of comparison for verification of the dimensions calculation of various supersonic nozzles. It provides a uniform and parallel flow at the exit section by the method of characteristics and the Prandtl Meyer function (Zebbiche \& Youbi, 2005a, 2005b, Zebbiche, 2007, Zebbiche, 2010a \& Zebbiche, 2010b). The thermodynamic ratios can be used to determine the design parameters of the various shapes of nozzles under the basis of the HT model.

We can obtain the relations of a perfect gas starting from the relations of our model by annulling all constants of interpolation except the first. In this case, the PG model becomes a particular case of our model.

\section{Acknowledgment}

The author acknowledges Djamel, Khaoula, Abdelghani Amine, Ritadj Zebbiche and Fettoum Mebrek for granting time to prepare this manuscript.

\section{References}

Anderson J. D. Jr.. (1982), Modern Compressible Flow. With Historical Perspective, (2nd edition), Mc Graw-Hill Book Company, ISBN 0-07-001673-9. New York, USA.

Anderson J. D. Jr. (1988), Fundamentals of Aerodynamics, (2nd edition), Mc Graw-Hill Book Company, ISBN 0-07-001656-9, New York, USA.

Démidovitch B. et Maron I. (1987), Eléments de calcul numérique, Editions MIR, ISBN 978-27298-9461-0, Moscou, USSR.

Fletcher C. A. J. (1988), Computational Techniques for Fluid Dynamics: Specific Techniques for Different Flow Categories, Vol. II, Springer Verlag, ISBN 0-387-18759-6, Berlin, Heidelberg.

Moran M. J., (2007). Fundamentals of Engineering Thermodynamics, John Wiley \& Sons Inc., $6^{\text {th }}$ Edition, ISBN 978-8-0471787358, USA

Oosthuisen P. H. \& Carscallen W. E., (1997), Compressible Fluid Flow. Mc Grw-Hill, ISBN 007-0158752-9, New York, USA.

Peterson C.R. \& Hill P. G. (1965), Mechanics and Thermodynamics of Propulsion, AdditionWesley Publishing Company Inc., ISBN 0-201-02838-7, New York, USA.

Ralston A. \& Rabinowitz P. A. (1985). A First Course in Numerical Analysis. (2nd Edition), McGraw-Hill Book Company, ISBN 0-07-051158-6, New York, USA.

Ryhming I. L. (1984), Dynamique des fluides, Presses Polytechniques Romandes, Lausanne, ISBN 2-88074-224-2, Suisse.

Zebbiche T. (2007). Stagnation Temperature Effect on the Prandtl Meyer Function. AIAA Journal, Vol. $45 \mathrm{~N}^{\circ}$ 04, PP. 952-954, April 2007, ISSN 0001-1452, USA

Zebbiche T. \& Youbi Z. (2005a). Supersonic Flow Parameters at High Temperature. Application for Air in nozzles. German Aerospace Congress 2005, DGLR-2005-0256, 26-29 Sep. 2005, ISBN 978-3-8322-7492-4, Friendrichshafen, Germany. 
Zebbiche T. \& Youbi Z., (2005b). Supersonic Two-Dimensional Minimum Length Nozzle Conception. Application for Air. German Aerospace Congress 2005, DGLR-2005-0257, 26-29 Sep. 2005, ISBN 978-3-8322-7492-4, Friendrichshafen, Germany.

Zebbiche T. \& Youbi Z. (2006), Supersonic Plug Nozzle Design at High Temperature. Application for Air, AIAA Paper 2006-0592, 44 $4^{\text {th }}$ AIAA Aerospace Sciences Meeting and Exhibit, 9-12 Jan. 2006, ISBN 978-1-56347-893-2, Reno Nevada, Hilton, USA.

Zebbiche T., (2010a). Supersonic Axisymetric Minimum Length Conception at High Temperature with Application for Air. Journal of British Interplanetary Society (JBIS), Vol. 63, N 04-05, PP. 171-192, May-June 2010, ISBN 0007-084X, 2010.

Zebbiche T., (2010b). Tuyères Supersoniques à Haute Température. Editions Universitaires Européennes. ISBN 978-613-1-50997-1, Dudweiler Landstrabe, Sarrebruck, Germany.

Zuker R. D. \& Bilbarz O. (2002). Fundamentals of Gas Dynamics, John Wiley \& Sons. ISBN 0471-05967-6, New York, USA 


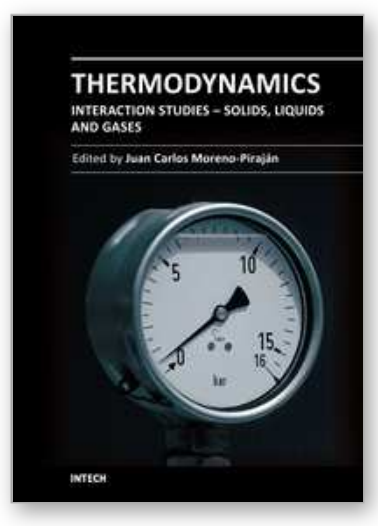

\author{
Thermodynamics - Interaction Studies - Solids, Liquids and Gases \\ Edited by Dr. Juan Carlos Moreno Pirajễin
}

ISBN 978-953-307-563-1

Hard cover, 918 pages

Publisher InTech

Published online 02, November, 2011

Published in print edition November, 2011

Thermodynamics is one of the most exciting branches of physical chemistry which has greatly contributed to the modern science. Being concentrated on a wide range of applications of thermodynamics, this book gathers a series of contributions by the finest scientists in the world, gathered in an orderly manner. It can be used in post-graduate courses for students and as a reference book, as it is written in a language pleasing to the reader. It can also serve as a reference material for researchers to whom the thermodynamics is one of the area of interest.

\title{
How to reference
}

In order to correctly reference this scholarly work, feel free to copy and paste the following:

Toufik Zebbiche (2011). Effect of Stagnation Temperature on Supersonic Flow Parameters with Application for Air in Nozzles, Thermodynamics - Interaction Studies - Solids, Liquids and Gases, Dr. Juan Carlos Moreno PirajÃ $i n(E d),. ~ I S B N$ : 978-953-307-563-1, InTech, Available from:

http://www.intechopen.com/books/thermodynamics-interaction-studies-solids-liquids-and-gases/effect-ofstagnation-temperature-on-supersonic-flow-parameters-with-application-for-air-in-nozzles

\section{INTECH}

open science | open minds

\section{InTech Europe}

University Campus STeP Ri

Slavka Krautzeka 83/A

51000 Rijeka, Croatia

Phone: +385 (51) 770447

Fax: +385 (51) 686166

www.intechopen.com

\section{InTech China}

Unit 405, Office Block, Hotel Equatorial Shanghai

No.65, Yan An Road (West), Shanghai, 200040, China

中国上海市延安西路65号上海国际贵都大饭店办公楼405单元

Phone: +86-21-62489820

Fax: +86-21-62489821 
(C) 2011 The Author(s). Licensee IntechOpen. This is an open access article distributed under the terms of the Creative Commons Attribution 3.0 License, which permits unrestricted use, distribution, and reproduction in any medium, provided the original work is properly cited. 